\title{
Surgical Controversy at the New Hospital for Women, 1872-1892
}

In 1890, looking back upon nearly half a century of successful abdominal surgery, Sir Thomas Spencer Wells lauded the 'energetic spirit of inquiry' which had characterised this period and had led to 'hands delicately and expressly trained' for surgical endeavour. Such 'life-giving and health preserving work' promised influence, 'dignity and distinction' to the 'supremely beneficent' surgeon. ${ }^{1}$ Yet surgery still had an aura of butchery surrounding it, with the surgeon viewed as an aspiring rather than actual gentleman. ${ }^{2}$ The development of antiseptic and aseptic procedures may have made surgery less painful both for patient and operator but, as Michael Worboys has shown, theoretical advance was not always followed by practical adoption. ${ }^{3}$ Abdominal surgery especially was visceral, bloody and brutal, and, by implication, so was the abdominal surgeon. Spencer Wells' account of surgical progress, with its fastidious and benevolent tone, sought to counter such objections with a record of innovation, development and perfection, coupled with the 'honourable feeling and highly cultivated judgment' of the thoughtful surgeon. This spirited defence of surgical practice sought to challenge doubters both within and without the profession of the wisdom of entering the abdomen. Some of the most virulent controversy surrounded abdominal surgery on women; the surgeon demonised in popular culture as a human vivisector, experimenting dangerously and without a care upon the defenceless female, robbed of her organs of generation. Ovariotomy was considered both 'the starting point in the modern advance of abdominal surgery', as Wells put it, and a practice considered initially as 'little short of

${ }^{1}$ British Medical Journal (hereafter BMJ), 27 December 1890, p. 1468.

${ }^{2}$ For more on the representation of surgeons throughout the ages, see Lawrence in Lawrence (ed.) 1992; Lawrence in Lawrence and Shapin (eds) 1998.

\footnotetext{
${ }^{3}$ Worboys, 2000.
} 
murder'. ${ }^{4}$ With such a history, abdominal surgery, particularly that practised upon women, was both momentous progress and barbaric regression.

In Women Under the Knife: A History of Surgery, Ann Dally explores the surgical dilemma facing medical women, asking whether women, in the light of this controversy over abdominal surgery, were 'anxious to wield the scalpel themselves'. She concludes that, while some, such as Elizabeth Garrett Anderson, operated on their own sex, many more 'tended to practise in "gentler fields", 5 Dally's use of 'anxious' here can be interpreted in two ways. First, keen, enthusiastic and eager; and, secondly, worried, troubled, fraught. It is this dual anxiety for the woman surgeon herself that I wish to explore in this article. In doing so, I will focus on surgical procedure at one London hospital, the New Hospital for Women, as a case study. This allows a new perspective on how women surgeons operated, and also reflection about the consequences of surgical risk and innovation upon the patient, the surgeon and the hospital itself. If risk is key, as Thomas Schlich puts it, to "whether a medical novelty gets accepted or not' and an integral part of negotiating the potential benefits and dangers of surgery, what happened when female surgeons, themselves medical novelties, took surgical risks? ${ }^{6}$

\section{Beginnings}

The New Hospital for Women grew out of the foundation of St Mary's Dispensary in 1866. From the outset, the Dispensary had a dual purpose, combining philanthropy with solid practical support for women doctors, who were exclusively to form the working medical

\footnotetext{
${ }^{4}$ Moscucci, 1990, p. 134.

${ }^{5}$ Dally, p. 199; p. 201.

${ }^{6}$ Schlich in Schlich and Tröhler (eds) 2006.
} 
staff. It would 'meet a want in a large and poor district of London, and at the same time to assist the movement in favour of admitting women into the medical profession'. ${ }^{7}$ Between its foundation in 1866 and its transformation into the New Hospital in early 1872, the Dispensary was flooded with women both from the metropolis and from elsewhere seeking specifically the medical assistance of their own sex. The sheer demand for the services of the Dispensary, coupled with the desperate state of many of the patients, who were too ill to attend in person, and their homes too poor and dirty to permit surgical attendance, encouraged the Dispensary Committee to provide proper hospital accommodation to house a new and expanded facility. While the influx of potential patients contributed to the conversion from Dispensary to Hospital, the Committee noted that it was increasingly necessary, '[i]n very many cases', to offer treatment that was 'almost purely surgical'. ${ }^{8}$ The performance of surgical procedures and the foundation of the New Hospital for Women were inextricably linked in the eyes of the management and staff of the Hospital. As Mary Ann Elston has noted, in the second half of the nineteenth century hospitals were founded through 'a mixture of philanthropic, professional and entrepreneurial motives', and the New was an institution "where women could develop professional skills and achieve positions of responsibility from which they were otherwise excluded, both by overt opposition and by the limited mandate under which nineteenth-century women entered medicine' ${ }^{9}$ In a list of desirable 'professional skills' and in opposition to the contemporary expectations of the medical profession, surgical expertise was considered vital for the promotion of women doctors. As the first Annual Report of the hospital was so keen to publicise, successful

\footnotetext{
7 London Metropolitan Archives (hereafter LMA), H13/EGA/01/001, New Hospital for Women (hereafter NHW) Annual Report 1873.

${ }^{8}$ Ibid.

${ }^{9}$ Elston in Hardy and Conrad (eds) 2001, p. 85.
} 
surgery performed by skilful surgeons was a key aim of the New from its inception. By 1900, indeed, $57.6 \%$ of in-patients were surgical, with a third of those undergoing 'major operations'. ${ }^{10}$

The Annual Reports list that the all-female staff were assisted by a consulting staff, who were exclusively male. While the assumption was that the female staff would carry out operations, in fact it appears that they, at least in the first decade or so of the New's existence, actually acted as assistants to the more experienced consulting surgeons. In her 1924 Reminiscences, Mary Scharlieb, who joined the New as a Clinical Assistant in 1888, makes reference to the peculiarities of this situation. Discussing the operations at the Hospital, Scharlieb recalls that Elizabeth Garrett Anderson was the

one member of the staff who undertook major surgery, it was she only who was competent, and indeed she was the only one who was willing to encounter the difficulties and responsibilities inseparable from such work. Sometimes she felt that in the interests of the patient a surgeon of greater experience ought to operate. When this occurred no self-love nor false shame prevented Mrs Anderson from inviting some outside surgeon to do what was necessary. On such occasions she played the part of assistant. ${ }^{11}$

Far from embracing surgery as willingly as the Management Committee would have the public believe, the female medical staff acknowledged their own limitations, stepping back to observe procedures rather than wielding the knife themselves.

\section{Resignations}

\footnotetext{
${ }^{10}$ LMA, H13/EGA/05/005, NHW Annual Report 1901, p. 11.

${ }^{11}$ Scharlieb 1924, p. 133.
} 
While the female staff remained assistants rather than operators, there was a chasm between the mission statement of the New and the actual practice which occurred within its walls. Although she 'knew the limits of her training', Elizabeth Garrett Anderson sought to change procedures, insisting that medical women should do the professional work of the hospital. ${ }^{12}$ Both Louisa Garrett Anderson and Mary Scharlieb note that Elizabeth Garrett Anderson was the only member of staff willing to undertake major surgery, and her desire to promote the cause of the female surgeon encountered numerous difficulties from her fellow medical women. Although both women express her dedication to education through practice, they also reveal Garrett Anderson's fear of her own surgical inadequacies; hence her willingness 'meekly' to assist or observe. According to her daughter, each operation caused Garrett Anderson 'intense anxiety', ensuring that she 'never enjoyed operating'. ${ }^{13}$ Too often, the reaction of the surgeon to surgical procedures is forgotten in the history of medicine; the fear and distress surgery provoked was not only that of the patients. ${ }^{14}$ For early women surgeons, who were compelled to learn by experience, a lack of specialised training rendered every operation a risky and potentially frightening process. In a manuscript draft for a speech, Elizabeth Garrett Anderson remarked feelingly upon and, evidently, with personal understanding of, the effect surgery had upon the operator:

To see a skilled surgeon do his work is a very different thing from doing it oneself. . . In surgery the nerve has to be trained and that only is done by actual work of your own. I believe it is impossible for any but those who have gone through it to realise what a tremendous tax upon one's nerve it is to attempt a great operation, especially of the kind where exact previous

\footnotetext{
${ }^{12}$ Garrett Anderson 1939, pp. 242-3.

${ }^{13}$ Garrett Anderson 1939, p. 242.

${ }^{14}$ See Stanley 2003, especially pp. 203-4.
} 
knowledge of the difficulties cannot possibly be had. I speak of this with feeling because I know what it is. ${ }^{15}$

From a generalised opening, Garrett Anderson's constant repetition of the personal pronoun, especially prominent in the last sentence, implies that holding 'one's nerve' was far from a given attribute for the surgeon. Training was essential, but when this was limited by circumstances, risks had to be taken. Behind the celebration of the calm, skilful female surgeon in the New's Annual Reports and other forms of publicity lay a more nervy reality, where ability was questioned and doubted.

If self-doubt was evident at the New, then a spate of resignations over the period between 1877 and 1888 revealed that concern at women performing surgical procedures was pervasive. Much has been made in previous accounts of the first of these controversial departures, Frances Hoggan's resignation in 1877, but other cases have been entirely passed over. Indeed, the date and circumstances of Hoggan's leaving have been confused and conflated to the extent that she appears to have resigned over operations which were not carried out until a year after she left the New. ${ }^{16}$ Although there is indecision over when Hoggan actually left the New, there is none when it comes to why: Hoggan resigned because of controversial surgical procedures being performed by women on women.

The Minute Books of the Managing Committee of the New, however, confirm that Frances Hoggan tendered her resignation in March 1877, giving no reason other than that she 'had quite made up her mind to take this step', and was emphatically 'Resolved' [sic] in her decision to leave. Forced, reluctantly, to accept, the Committee noted that Hoggan's 'kind

${ }^{15}$ Manton 1965, p. 230.

${ }^{16}$ Garrett Anderson 1939, p. 243, names 1876. Elston 2005 and Elston 2004 suggest 1872 and 1878 respectively. 
and skilful labours have done much to the raise the Hospital to its present position', and that they felt sure her departure would be regretted both by supporters and patients alike. ${ }^{17}$ The next meeting, exactly a month later, recorded Frances Hoggan's gratitude at the Committee's praise, but also her willingness to continue working at the New on her usual Tuesdays and Fridays until they had found a replacement. ${ }^{18}$ Examining the cases listed in the Annual Report for 1877 does not elicit any evidence of an ovariotomy, successful or otherwise, having been performed that year. In 1876, however, two operations are noted specifically, neither ovariotomies: one recto-vaginal fistula; the other a ruptured perineum. The former failed, and the latter was postponed. One of the three deaths that year arose from complications following an operation to remove a cancerous breast. This appears to have been a tricky case, involving several operations, and resultant gangrene, which in turn led to the Hospital succumbing to 'erysipelas and some of the allied diseases'. The 'grave anxiety' resulting from the spread of this deadly infection is evident in the Annual Report for the year, where relief at the containment of the outbreak is palpable:

Happily all the patients so attacked eventually recovered, but it was thought necessary to empty the hospital for two months, and to have the wards repainted and whitewashed. Since this was done, all the surgical cases have recovered well, and nothing has again occurred to give rise to any suspicion as to the good sanitary condition of the hospital. ${ }^{19}$

As a key member of the anti-vivisectionist Victoria Street Society and someone who appeared to ally herself with the ideas of Elizabeth Blackwell, Hoggan may have objected to

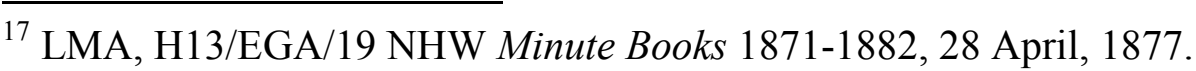

${ }^{18}$ LMA, H13/EGA/19 NHW Minute Books 1871-1882, 28 May, 1877.

${ }^{19}$ LMA, H13/EGA/01/005, NHW Annual Report 1877, p. 3. 
certain surgery involving what Blackwell labelled the 'serious ethical danger connected with unrestrained experiment on the lower animals [which leads to] the enormous increase of audacious human surgery, which tends to overpower the slower but more natural methods of medical art and to divert attention from hygiene'. ${ }^{20}$ Maybe, given her political stance, Frances Hoggan did resign over the prospect of female surgeons cutting up their own sex, or because surgical procedures, as they were carried out at the Hospital, could be far too risky, as the events of 1876 revealed. But, she did not leave the Hospital in 1877 because Garrett Anderson was performing ovariotomies, either on her own or with support from the consulting staff.

In fact, the first time this controversial procedure was carried out was a year after the departure of Frances Hoggan, in 1878. As the Annual Report trumpeted:

During the year the operation of ovariotomy has been twice performed by a member of the Hospital staff, once in private, and once in the Hospital, and in each case the patient has recovered perfectly. The Committee are not aware of this formidable operation having been ever before, in Europe at least, performed successfully by a woman. ${ }^{21}$

If they had objected to the procedure previously, the response was not recorded, and here the only tone is one of triumph and pride in Garrett Anderson's achievement. ${ }^{22}$ Even though she

${ }^{20}$ Blackwell 1902, p. 119. For general background information on Hoggan, see Thomas 1971. For more on Hoggan's anti-vivisectionist activities, see Elston in Rupke (ed.) 1987, pp. 259-94.

${ }^{21}$ LMA, H13/EGA/02/001, NHW Annual Report 1879, p. 3.

${ }^{22}$ Manton 1965 notes that 'the management committee refused to allow the operation to take place in the hospital [but after the success of this first operation] the next case remained in the hospital' (p. 229). 
is not named directly, the anonymity serves to reflect the glory back upon the New Hospital for Women as an institution which nurtured female surgical expertise. However, in this report, the Management Committee were also compelled to report that, along with Hoggan's departure, the New had lost another member of staff: John Erichsen, one of the consulting surgeons. Erichsen had been a surgical advisor to the female staff from the Hospital's Dispensary foundations. After twelve years of assistance, Erichsen left in April 1878, but continued to 'entertain the most friendly feelings towards the Institution'. ${ }^{23}$ As the renowned author of The Science and Art of Surgery (first published in 1853), a well-respected and widely used textbook, Erichsen's loss must have been a great disappointment; assistance from those established members of the profession who supported medical women's vital need for practical experience was greatly valued.

John Eric Erichsen had been made surgeon-extraordinary to Queen Victoria in 1876, and was Vice-President of the RCS between 1878 and 1879, becoming President in 1880. Lister had been one of his house surgeons, and, as his $B M J$ obituary noted in 1896, he should be counted 'among the makers of modern surgery', with 'his sound judgment, ripened by a vast experience, which gave him an almost unrivalled clinical insight. There was no man in the profession whose opinion in a difficult case was justly held to be of greater weight'. ${ }^{24}$ Only three years after his resignation from the New, Erichsen publicly expressed doubts over the supposed progress of abdominal surgery. The Science and Art of Surgery raised but did not support the objections to operations such as ovariotomy, concluding that the discomfort is

${ }^{23}$ LMA, H13/EGA/19 NHW Minute Books 1871-1882, 4 April 1878.

${ }^{24}$ For further biographical information on Erichsen, see his obituary in the $B M J, 26$ September 1896, pp. 885-87 (the given quotation is on p. 886); the entry for Erichsen at the RCS's Playne's Lives of the Fellows Online. Curiously, in none of these entries is there any mention of his long involvement with the New. 
worse without action and patient death rates are not so high as other procedures to warrant surgeons abstaining from the process. ${ }^{25}$ And yet, by August 1881, in a lecture given at the BMA Annual Meeting Erichsen acknowledged the 'brilliant advance' made in abdominal surgery, but felt troubled by its increasingly alarming experimental nature:

[are they] surgical triumphs or operative audacities [?] There must, indeed, be a limit to the progress of operative surgery in this direction. [. . .] May there not be some reason to fear lest the very perfection to which ovariotomy has been carried may lead to an over-sanguine expectation of the value and the safety of the abdominal section, and exploration when applied to the diagnosis or cure of diseases of other and very dissimilar organs, in which but little of ultimate advantage, and certainly much of immediate peril, may be expected from operative interference ${ }^{26}$

Was it concern at 'operative audacity', or at least the potential for a too sanguine acceptance of mortality through experimentation, which encouraged Erichsen to resign his consulting post at the New? If he anticipated the growth of such procedures then he was to be proved correct. From 1888, a storm of controversy hit the New, as female surgeons made a break with the past, and, controversially, took the lead in their own operations.

\section{Divisions}

Despite Elizabeth Garrett Anderson's desire for the female medical staff at the New to perform surgical procedures themselves, they were still not always doing so by the mid1880s. In March 1884, when a patient's death under anaesthetic was reported in The

\footnotetext{
${ }^{25}$ Erichsen 1864, pp. 1234-35.

${ }^{26}$ Erichsen 1881, pp. 212-14.
} 
Paddington Times, which also covered the resultant inquest, it was evident that Garrett Anderson was only 'present' at the operation, while W.A. Meredith was to perform the surgery. ${ }^{27}$ While she had apparently operated alone successfully for the two ovariotomies in 1878 , subsequent results were not so pleasing. When a patient died from an ovarian tumour and consequent peritonitis, the Annual Report for the year 1879 was keen to stress that no operation had been performed in this case. ${ }^{28}$ The Management Committee was evidently conscious of the ongoing sensitivity of the subject and wanted to protect the New from accusations of improper conduct. In 1880, though, it was noted that there had been an inpatient death from a suppurated ovarian cyst, where ovariotomy was placed in brackets after the cause of death. The patient had died after the operation, but bracketing the procedure ensured that the cause of death was recorded as the suppurated cyst. ${ }^{29}$ A similar case took place in 1881 , whereby the patient had succumbed to bronchitis after an ovariotomy for an ovarian cyst. It was added, at the beginning of the report, that this patient was $69 .{ }^{30}$ As the Minutes of the Hospital noted, it was Garrett Anderson herself who prepared the Annual Report, so a careful public presentation of controversial procedures was in the interest of the staff and, of course, the Hospital, in the eyes of its subscribers and those who followed the careers of medical women.

While it is not clear precisely who was assisting whom in surgery, the impression given by the Hospital was that the women were performing their own procedures at this point.

${ }^{27}$ LMA H13/EGA/144 Album of Newspaper Cuttings: 'Correspondence: Melancholy Death in the Hospital for Women, 222, Marylebone-Road', The Paddington Times, Saturday 15 March, 1884, and an undated article from the same paper recording the inquest.

${ }^{28}$ LMA, H13/EGA/02/002 NHW Annual Reports 1880, p. 15.

${ }^{29}$ LMA, H13/EGA/02/003 NHW Annual Reports 1881, p. 15.

${ }^{30}$ LMA, H13/EGA/02/004 NHW Annual Reports 1882, p. 11; p. 3. 
However, cross referencing the Hospital records with statistics presented in print by members of the consulting staff about their operations offers a fascinating glimpse into how involved the supposed consultants to the New really were in day-to-day surgery. In May 1882, Elizabeth Garrett Anderson proposed, and was unopposed, that W.A. Meredith be appointed Consulting Surgeon. ${ }^{31}$ Previously an assistant to John Erichsen, Meredith had also assisted Spencer Wells, one of the foremost abdominal surgeons in Britain at the time, and was clearly an impressive addition to the list of consultants. ${ }^{32}$ In 1889 , Meredith published 'Remarks on some parts affecting the Mortality of Abdominal Section', which was illustrated with 'Tables of Cases'. Table I was a list of 'One Hundred and Four Completed Ovariotomies' and Table II listed twelve 'Operations for the Removal of Diseased Uterine Appendages'. Of these cases, seven were from operations undertaken at the New between 1882 and 1887; five ovariotomies and two removals of appendages. Indeed, as New's Annual Report remarked, the increase in surgical cases was evident from 1882, when the very fabric of the Hospital began to alter because of the focus on surgery. The average number of in-patients declined due to 'the presence in the Hospital of a larger number of serious surgical cases, each one of which has frequently occupied an entire ward for several weeks' ${ }^{33}$ In 1882, there is one operation noted for an ovarian tumour, which tallies with Meredith's list concerning his procedure at the New this year. ${ }^{34}$ Although Garrett Anderson had been lauded for her successful performance of two ovariotomies in 1878 , by 1882 , perhaps after the deaths recorded in the first two years of the decade, she was clearly not the surgeon carrying

\footnotetext{
${ }^{31}$ LMA, H13/EGA/20 NHW Minute Books 1882-1895, Wednesday 4 May 1882.

32 'Obituary: William Appleton Meredith', BMJ 14 October 1916, p. 542.

${ }^{33}$ LMA, H13/EGA/02/005 NHW Annual Reports 1883, p. 3.

${ }^{34}$ LMA, H13/EGA/02/005 NHW Annual Reports 1883, p.10: number 29; Meredith 1889, pp. 31-56; p. 45.
} 
out the procedure at the Hospital. During 1882, indeed, there was only one death over the entire year, out of the 205 patients admitted into the Hospital. The previous year had witnessed five deaths out of 221 patients.

With Garrett Anderson in Australia from January to the Autumn of 1885, the two operations noted as 'ovarian cyst' in the Annual Report for this year were performed by Meredith. ${ }^{35}$ Two years later, in 1887 , the patient with a dermoid ovarian cyst was also Meredith's. ${ }^{36}$ The majority of ovariotomies occurred in 1886, however. The Annual Report states that were three operations for ovarian cyst that year, with one death; Meredith's patient survived, according to the statistics noted in the Medical-Chirurgical Transactions. ${ }^{37}$ It is therefore likely that the patient who died was operated upon by Garrett Anderson, whose success rate was $50 \%$ that year. She had written this year enthusiastically to her husband, who was in America, about the 'excellent' recovery of her patient and the removal of a tumour, which had been 'a very uncommon case' and which had, consequently, been offered 'to the Museum of the College of Surgeons as [Sir Spencer] Wells says they have only one like it'. ${ }^{38}$ This was not the last time Garrett Anderson felt misplaced confidence about her patients' futures after surgical intervention. It was this discrepancy between surgical

${ }^{35}$ For information about Garrett Anderson's absence, see Scharlieb, Reminiscences, p.133 and LMA, H13/EGA/20 NHW Minute Books 1882-1895, Wednesday, 7 January 1885.

The operations performed at the New are listed in Meredith 1889, case 66 and case 74, pp. 48-9; and LMA, H13/EGA/03/002 NHW Annual Reports 1886, number 21, p. 12.

${ }^{36}$ Meredith 1889, case 98, p. 51; LMA, H13/EGA/03/004 NHW Annual Reports 1888, number 27, p. 12 .

37 Meredith 1889, case 87, p. 50; LMA, H13/EGA/03/003 NHW Annual Reports 1887, number 17, p. 12.

${ }^{38}$ Garrett Anderson 1939, pp. 243-4. 
ambition and operative success which led to resignations from the New in 1888; a year of staff losses which were instigated by Meredith himself, alarmed at what he witnessed during operations at the Hospital.

Three departures from the New Hospital for Women in 1888 reveals uncertainty not only over the question of female surgical aptitude, but also places a question mark over what Mary Ann Elston has called 'the nucleus of a professional and a friendship network that sustained pioneering generations' in the earliest women's hospitals. ${ }^{39}$ While Meredith was the first to leave, he was swiftly followed by Louisa Atkins and Mary E. Dowson, implying that female camaraderie was dissolving quickly. Both women were renowned in different, but equally important, ways in the history of women's attempt to enter the medical profession. Louisa Atkins secured a controversial post as a house surgeon in 1872 at the Birmingham and Midland Hospital for Women, when she was pitted against, and beat, two men in the final stages. This, as the $B M J$ noted, was a 'novel' announcement: 'the first appointment of the kind which has been opened to ladies in this country'. ${ }^{40}$ In Birmingham, she had worked with one of the most important surgeons of the era investigating the diseases of women: Lawson Tait. Indeed, when Atkins left in 1874, the philanthropic physician Thomas Heslop, who had been one of the initiators of the Hospital for Women in the city, stated feelingly that: 'the accession of that lady to the number of practitioners of surgery would be welcomed, and upon leaving that hospital, she would leave behind her a reputation, which he trusted would serve

${ }^{39}$ Elston in Hardy and Conrad (eds) 2001, p. 85.

${ }^{40}$ BMJ 8 June 1872 , p. 616 . The advertisement, in the same issue, read: 'BIRMINGHAM AND MIDLAND HOSPITAL FOR WOMEN-Resident Medical Officer and Secretary: $£ 50$ per annum, board, lodging, and washing', p. 627. For an examination of Atkins' career in the Birmingham context, see Reinarz 2009, pp. 90, 160; Lockhart 2008, pp. 62-103. 
her most essentially in her whole future life' ${ }^{41}$ Louisa Atkins had proved that women doctors could work alongside men, and gain their respect and trust, even in surgical cases. Mary Dowson's achievements were equally vital in the medical women's, and, most importantly, the female surgeon's, cause. Dowson had the 'honour', as the BMJ put it in the summer of 1886, of becoming 'the first woman admitted as a surgeon on the roll of the Royal College of Surgeons in Ireland', thus becoming the first qualified female surgeon. ${ }^{42}$ She had been working officially as the pathologist and unofficially as a 'chloroformist' at the New since 1886 , but had taken advantage of the RCSI taking the unprecedented step in opening their doors to women in 1885 to secure surgical qualifications. To lose these women, known, both within the medical profession and widely amongst the newspaper and periodical-reading lay public, as surgical pioneers, was a double blow for the New.

In the Minutes of the Management Committee Meeting of Wednesday, 1 February, 1888 it is recorded that Meredith had felt 'obliged' to resign his post as consulting surgeon, and that Thornton has already been engaged in his place. The Annual Report for 1887, published in March 1888, subsequently offers a statement about the 'valuable assistance' he has given 'to the surgical work of the Hospital' over a five-year period. ${ }^{43}$ The suggestion of Meredith's helping out here rather than actually undertaking many major operations reveals how keen the Hospital was to give the impression that the female staff were taking the lead in clinical work. A protest lodged by Louisa Atkins at the same meeting in which Meredith's

${ }^{41}$ Women and Work 29 August 1874, p. 4.

${ }^{42}$ BMJ 12 June 1886, p. 1124.

${ }^{43}$ LMA, H13/EGA/20 NHW Minute Books 1882-1895, Wednesday 1 February 1888; LMA, H13/EGA/03/04 NHW Annual Reports 1888, p. 6. 
resignation was tendered offered a fascinating glimpse into the inner workings of the Hospital hierarchy, whereby Garrett Anderson's keenness to uphold the New's purpose as a hospital where female medical talents were nurtured was becoming more and more vehement. Proposing that Mary Scharlieb become her clinical assistant at operations, Garrett Anderson encountered a frustrating negative from Louisa Atkins, who was not convinced by Scharlieb's surgical competence, and stated unequivocally that she would herself resign if the Committee did not allow her to send serious operation cases to other hospitals if Scharlieb and Garrett Anderson were to work as a surgical team. This dissension from the New's remit as a hospital which supported the clinical ambitions of women doctors presented a shocking ultimatum to the Committee.

It was, however, clearly a step too far, as the next meeting began with a letter, quoted verbatim in the minutes, from Louisa Atkins, detailing her objections to the proposed arrangement:

Dear Sir,

Referring to the conversation which took place at the last meeting of the Management Committee relative to the present system of operating for abdominal diseases at this Hospital I shall feel much obliged if you will lay my views before the Committee for their consideration.

Hitherto skilled assistance has been applied by Mr Meredith at every serious operation. This assistance is now lacking and I firmly believe that without such assistance the performance of abdominal sections at this Hospital will be injurious to the patients, to the cause of medical women and to the Hospital itself. 
Feeling this I could not justify it to my conscience to allow any patient of mine to be operated under the present system. I therefore ask the Committee to consider whether they can allow me either to send my patients to be operated at the Samaritan or to ask Mr Thornton whether he will consent to operate them at the NHW, or, should they consider both these propositions impracticable, whether they can make any other arrangement which will ensure the best interests of the patients.

Otherwise nothing remains for me but to resign my post though I shall do so with great regret for the loss of the post itself and a very real sorrow for the necessary severance from a colleague with whom I have worked amicably or so many years. I am dear Sir

Yours faithfully,

\section{Louisa Atkins. $^{44}$}

What is most noticeable here is that Atkins confirms the extent to which Meredith had been present at 'every serious operation'. While Atkins suggests that Scharlieb is not competent to assist, she also effectively reflects on Garrett Anderson's lack of confidence in operating alone. ${ }^{45}$ Such an assessment of the potential disaster awaiting patients in the hands of women surgeons was a stark warning to the Management Committee about the paucity of female surgical experience and training.

The Management Committee responded in an intriguing way. Rather than disregard Louisa Atkins' point, they agreed that although it was not advisable for the reputation of

${ }^{44}$ LMA, H13/EGA/20 NHW Minute Books 1882-1895, Wednesday, 22 February 1888.

${ }^{45}$ Scharlieb's surgical experience was, as she herself admitted, rudimentary in Madras; she had been assisted by her maid, with her sister as anaesthetist, Scharlieb 1924, pp. 110-11. 
woman doctors and the status of the New itself to send surgical patients elsewhere, they did not want to lose Dr Atkins from the staff and would, therefore, ask a reputable witness to comment on Garrett Anderson's surgical technique. Thornton was also appointed in Meredith's wake; but, it is clear that Meredith's departure encouraged Garrett Anderson to take direct charge of surgical procedures, something which clearly worried Atkins. The original focus on Scharlieb's capabilities has now disappeared and it is Garrett Anderson who is wholly under scrutiny, suggesting that this is where Atkins' original concern really lay. As Thomas Schlich has noted, historically-focused studies of risk taking can assess whether potential threats to health can be found to originate in the environment, in individual behaviour or in medicine itself. ${ }^{46}$ By focusing on Garrett Anderson's competence and skill, rather than environmental concerns or surgical practice in general, Atkins stressed the significance of individual behaviour in surgery. But, in so doing, Atkins reflected attention back upon wider concerns about women performing surgery, unsuccessfully and unskilfully, in a hospital environment. It is also telling that the idea of submitting Garrett Anderson to independent verification came from Garrett Anderson herself, perhaps both to protect her own surgical standing, as well as, given her doubts about operating, to reassure herself of her abilities. The receipt of Atkins' complaint further compelled Garrett Anderson to report on every operation to the Committee, as well as, from this point, the recording of every surgical procedure in the Annual Report for wider public perusal. Members of the Hospital staff and management evidently felt some sensitivity about surgical competence to clarify the facts and figures at precisely the same time as undergoing internal divisions over precisely this issue.

Louisa Atkins was, however, not mollified by such an offer. The controversy had exposed a rift among the medical staff which only widened over the next couple of months. The independent witness, Dr Bautock, refused to undertake an examination of Garrett

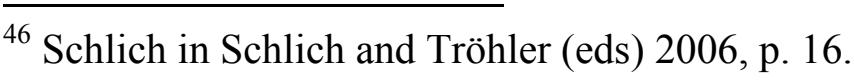


Anderson's surgery, as he felt that all operations in the Hospital should be performed, as had always been assumed, by the all-female staff. And so Garrett Anderson continued to operate. By late March 1888, Louisa Atkins issued an ultimatum: either she be allowed to send her patients to a choice of operating surgeons outside the Hospital, and thus away from Garrett Anderson, or she resign immediately. Atkins' resignation at the beginning of April came after she had, presumably by suggestion, witnessed another operation by Garrett Anderson, which, however,

did not in the least modify my opinion that she is not competent to undertake such operations singlehanded. I deeply regret the course taken by the Committee as it will assuredly confirm the growing opinions that in the minds of the Staff personal or collective advantage takes precedence over the sense of responsibility for the lives of the patients. ${ }^{47}$

The accusation here is that rather than act professionally in this instance, the Hospital are compelled to protect and bolster Garrett Anderson in her public image. What disgusted Louisa Atkins was that, as a subscriber to the New, the triple resignation, due entirely to 'conscientious motives' and concern for the patients, was effectively obscured from the outside world and that there was to be no enquiry into the reasons for the departure of three loyal members of staff. The Committee were dealt another blow in this meeting, as Mary Dowson also tendered her resignation for precisely the same reason as Louisa Atkins. Dowson's letter, less fulsome than Atkins', reflected upon her disagreement with the 'policy now pursued with regard to operations [which] precludes my working in harmony with the Medical Staff' ${ }^{48}$ By supporting Garrett Anderson, as the most senior woman doctor in the Hospital and the most renowned female medical pioneer in Britain, the Committee had lost

\footnotetext{
${ }^{47}$ LMA, H13/EGA/20 NHW Minute Books 1882-1895, Wednesday, 11 April 1888. ${ }^{48}$ Ibid.
} 
three valuable members of staff in as many months. It is telling that, in Atkins' obituary, mention is made of her 'excellent work' in Birmingham and the private practice which 'engaged her powers and absorbed her interest', but simply that she resigned from the New after holding her appointment for a number of years. Atkins' 'withdrawal from public life' after her resignation hints at her loss of faith in the position of women in the hospital system. $^{49}$ The cause of medical women and their right to perform surgery had been supported at the New, but only by disregarding the mistakes, which Atkins and Dowson had felt sufficiently serious to merit complaint.

In June 1888, Meredith wrote to clarify his reasons for departure. He 'found that the record of Mrs Anderson's operations at which he had been present shewed too high a percentage of failures', but that he 'should always retain a kindly feeling towards the Hospital and its staff' ${ }^{50}$ Subscribers, as predicted by Louisa Atkins, also expressed concern at the too evident problems within the 'internal workings' of the Hospital, and two wrote for clarification. They were pacified with the knowledge that a difference of opinion had resulted and that staff had resigned rather than been dismissed from their posts. ${ }^{51}$ In public, the summer of 1888 saw the launch of fundraising for new premises, whereby, in opposition to the surgical controversies of recent months, the phrases 'low death-rate' and 'skill, care

${ }^{49}$ BMJ, 1 Nov 1924, p. 836.

${ }^{50}$ LMA, H13/EGA/20 NHW Minute Books 1882-1895, Wednesday, 6 June 1888.

${ }^{51}$ A letter from Mrs Parish is mentioned in Ibid. Miss Wainwright's complaint about the ignorance in which subscribers were kept is mentioned in LMA, H13/EGA/20 NHW Minute Books 1882-1895, Wednesday 13 June 1888. 
and attention' formed a consistent refrain whenever the Hospital was mentioned. ${ }^{52}$ In June 1888, Elizabeth Garrett Anderson's surgical skills were witnessed and approved by the rather curious choice of Francis Imlach, a surgeon at the Women's Hospital in Liverpool, and a man who was no stranger to libellous remarks about his own capabilities. Only two years previously a scandal had threatened to end his career, when Imlach had been accused of performing unnecessary ovariotomies, and 'unsexing' his patients. Although he was acquitted of any wrongdoing, both in an internal enquiry and after a complaint from a patient's husband was rejected in court, Imlach's reputation, as well as the cause of radical surgical procedures for the diseases of women, received a setback. Garrett Anderson had been called upon as an expert for the report investigating Imlach's cases, and had concluded: 'It appears to me that the work done during the year is very creditable to the skill and courage of the medical staff of the hospital'. ${ }^{53}$ Imlach repaid her loyalty when it was Garrett Anderson's skills which were being brought into question by claiming: "'Have just witnessed as difficult an abdominal section as any surgeon could have to perform; and think that in technical skill and promptness I have never seen anything much more perfect". Francis

\footnotetext{
${ }^{52}$ See LMA, H13/EGA/144 Album of Newspaper Cuttings, where there are reports from the public meeting in aid of the Building Fund on 7 July 1888, including extracts from Daily Chronicle, City Press, The Times, and The Globe.

53 As quoted in Liverpool Mercury, Friday, 31 December 1886. See, especially, the correspondence from 'Justice', who laments that his wife was not informed of 'the consequences of the operation': 'are they told the extent to which the operation known as ovariotomy will incapacitate them?' (Monday 23 August, 1886).
}

For more on the 'Imlach Case', see Morantz-Sanchez 1999, pp. 127-8. 
Imlach' ${ }^{54}$ The original 'four or five' procedures originally suggested by Garrett Anderson herself in February, in order to appease Louisa Atkins, had been reduced to just one unidentified abdominal section.

With the backing of the Hospital's Management Committee and independent verification of her abilities, Garrett Anderson began to perform more complex and risky procedures 'entirely without outside help'; exactly what had been feared by Atkins. ${ }^{55}$ This was in line, as Sally Wilde argues, with the trend in the 1890 s, as procedures developed, for major, new surgery to be performed, which had never been attempted by the surgeon before. ${ }^{56}$ This, in turn, led to surgery, which was creative invention as much as scientific progress; surgeons learning from their mistakes through practical experience. ${ }^{57}$ Of course, with their lack of training, this is precisely how the woman surgeon had learnt her craft in the first place. Interestingly, soon after the triple staff resignations, oopherecetomies were first conducted in 1888. That year, Garrett Anderson was vindicated, as there was only one operation death out of 54 cases, and now they were listed separately for the first time, this success was even more evident. The following year there was only one death, again from an ovariotomy, this time from a total of 81 cases. $^{58}$ Over the next three years, the Hospital saw a move away from operations concentrating on the diseases of women and entered new surgical territory, with the introduction of ophthalmic surgery, as well as a the performance of a splenectomy in 1890, and nephrectomies from 1891. The latter operation had first been performed

\footnotetext{
${ }^{54}$ Reported in the minutes of Tuesday 26 June, 1888.
}

${ }^{55}$ Garrett Anderson 1939, p. 274.

${ }^{56}$ Wilde 2009, p. 316.

${ }^{57}$ Wilde and Hirst 2009.

${ }^{58}$ LMA, H13/EGA/03/005 NHW Annual Reports 1889, p. 18. 
successfully in Britain only six years before Garrett Anderson's attempt, by a member of New's consulting staff, Knowsley Thornton. ${ }^{59}$ Despite Thornton's experience, he had sworn after two further failures, where the patients bled to death, and the death four years later of his only successful case, never to perform this procedure again. ${ }^{60}$ Thus it appears that Garrett Anderson took the lead here; this is corroborated by her own words in a letter her sister Millicent Garrett Fawcett. Noting the rarity of the procedure she wrote:

I had a very big operation at the New yesterday and so far all promises very well with the patient [...] [I]f mine recovers it will be quoted for a long time. - I fancy too that [mine crossed out] the tumour in my case was larger than any yet. It was a much overgrown spleen. I tell you this for the sake of the cause. $^{61}$

Unfortunately, the patient died from septicaemia, so Garrett Anderson had achieved neither plaudits for the Hospital nor for the name of the female surgeon. Risk had been implemented

$\overline{59}$ Thornton 1886, pp. 407-17. Spencer Wells had unsuccessfully performed a splenectomy in 1865. Twelve out of the thirty-four operations had been performed in Britain, with Thornton's the only success (pp. 416-17). By December 1887, Spencer Wells had been successful. See Wells 1888, pp. 255-63. This had increased to two successes for Wells by the end of 1890. See Wells 1890, pp. 1465-8.

${ }^{60}$ Thornton 1896, pp. 513-17; p. 514.

In 1886, Lawson Tait also commented that splenectomy was an 'operation which I myself have not yet ventured to perform, and do not think that when performed for disease of the spleen [. . . ] is ever likely to be successful', Liverpool Mercury, Friday, 31 December 1886.

61 The Women's Library, 9/10/111 (ALC/3001), Elizabeth Garrett Anderson to Millicent Garrett Fawcett, 22 October 1890. 
at the New for 'the sake of the cause', precisely what had been feared by Louisa Atkins two years previously.

Between 1891 and 1892, six nephrectomies resulted in a $66.7 \%$ mortality rate; in 1888 , Lawson Tait had recorded, from twelve cases, two patient deaths, ensuring mortality was only $16.6 \%{ }^{62}$ There was an inevitable element of risk in performing new procedures such as this, but, with the surgical profession still acquiring confidence in itself, surgery at the New had to be carried out with an eye to innovation and progression if women were to operate as extensively as their male colleagues. When Garrett Anderson decided to hand over her post to her assistant Mary Scharlieb in the Autumn of 1892, forty-four major operations and abdominal sections had been performed, with a mortality rate of $13.6 \%$, more than double the previous year, when there were eighty-four cases (minus eye operations), but with only a 5.95\% mortality. Passing on her post, Garrett Anderson had been assisting others and performing surgery herself for twenty years. She had not been specially trained in the discipline, but then, as Mary Scharlieb put it, none of the early women medical pioneers were 'never able to be what is called pure physicians or pure surgeons. We had of necessity in those early days to be willing to give advice to women as to their health, whether from the medical, surgical or obstetric point of view'. ${ }^{63}$ Female medical staff at the New had proved that women could perform complex and difficult procedures. Women were able to operate no differently to their male comrades, who had received more specialist clinical and surgical training. However, while surgery revealed precisely what women could do, it also highlighted their limitations. The early female surgeon was forced to contend with her own difficulties,

${ }^{62}$ There were three operations in each year; with two deaths and one recovery at the New, LMA, H13/EGA/04/001-002 NHW Annual Reports 1891 and 1892, p. 20.

Tait 1888, pp. 1096-1100; p. 1100.

${ }^{63}$ Garrett Anderson quoted in Scharlieb 1924, p. 134. 
but she was also faced with opposition from her colleagues. If, as Garrett Anderson claimed, one could only become skilful though experience - 'no one can operate well who is not operating constantly' -, curtailing and disrupting practice was a regular feature of the first twenty years of the New Hospital for Women. ${ }^{64}$ Although the New was founded to support medical careers, surgery was one area in which male and female members of staff could unite against the progression of the woman surgeon.

${ }^{64}$ Garrett Anderson quoted in Scharlieb 1924, p. 134. 


\section{Bibliography}

\section{Primary Sources}

London Metropolitan Archives, London.

The Women's Library, London.

Liverpool Mercury.

Women and Work.

Blackwell, E., 1902, Essays in Medical Sociology, London: Bell.

Erichsen, J.E., 1881, 'An Address Delivered at the Opening of the Section of Surgery', $B M J$, 2.1075, pp. 212-14.

'H.S.' 1924, 'Obituary: Louisa Atkins, MD’, British Medical Journal, 2(3331), 836-7.

Erichsen, J.E., 1864, The Science and Art of Surgery. Being a Treatise on Surgical Injuries, Diseases, and Operations, Fourth Edition, London: Walton and Maberly.

Meredith, W.A., 1889, 'Remarks on some points affecting the Mortality of Abdominal Section. With Tables of Cases', Medico-Chirurgical Transactions, 72, pp. 31-56.

'H.S.', 1924, 'Obituary: Louisa Atkins, M.D.', BMJ, 2.3331, pp. 836-837.

Scharlieb M., 1924, Reminiscences, London: Williams and Norgate.

Tait, L., 1888, 'General Summary of Conclusions from a Second Series of One Thousand Consecutive Cases of Abdominal Section', BMJ, 2.1455, pp. 1096-1100

Thornton, K., 1896, 'A Lecture on the Lines of Advance in Abdominal Surgery. Being the Second Hunterian Society Lecture for the Session 1895-96', BMJ, 1.1835, pp. 513-17.

Thornton, K., 1886, 'Two Cases of Splenectomy', Medical Chirurgical Transctions, 69, pp. 407-17.

Wells, S., 1890, 'The Bradshaw Lecture on Modern Abdominal Surgery, Delivered at the Royal College of Surgeons of England', Dec $18^{\text {th }} 1890, B M J, 2.1565$, pp. $1465-8$. 
Wells, S, 1888, 'Remarks on Splenectomy, With a Report of a Successful Case', Medical Chirurgical Transactions, 71, pp. 255-63.

\section{Secondary Sources}

Dally, A., 1991, Women Under the Knife: A History of Surgery, London: Hutchinson Radius

Elston, M.A., 2005, 'Anderson, Elizabeth Garrett (1836-1917)', Oxford Dictionary of National Biography,

[http://www.oxforddnb.com/view/article/30406, accessed 5 March 2010].

Elston, M.A., 2004 'Hoggan, Frances Elizabeth (1843-1927)', Oxford Dictionary of National Biography [http://www.oxforddnb.com/view/article/46422, accessed 5 March 2010].

Elston M.A., 2001, “"Run by Women, (mainly) for Women”: Medical Women's Hospitals in Britain, 1866-1948, in Hardy A. and Conrad L. (eds) Women and Modern Medicine, Clio Medica: The Wellcome Series in the History of Medicine, 61, pp. 73-107.

Elston, M.A., 1987, 'Women and Anti-vivisection in Victorian England, 1870-1900', in Rupke, N.A. (ed), Vivisection in Historical Perspective, London and New York: Croom Helm, pp. 259-94.

Garrett Anderson, L., 1939, Elizabeth Garrett Anderson 1836-1917, London: Faber and Faber.

Lawrence, C., 1998, 'Medical Minds, Surgical Bodies: Corporeality and the Doctors', in Lawrence C. and Shapin S. (eds) Science Incarnate: Historical Embodiments of Natural Knowledge, Chicago, IL and London: University of Chicago Press, pp. 156-201.

Lawrence, C. 1992, 'Democratic, divine and heroic: the history and historiography of surgery', in Lawrence, C. (ed.) Medical Theory, Surgical Practice: Studies in the History of Surgery, London and New York: Routledge, pp. 1-47. 
Lockhart, J. 2008, 'Women, Health and Hospitals in Birmingham: The Birmingham and Midland Hospital for Women, 1871-1948', unpublished PhD thesis, University of Warwick.

Manton, J. 1965, Elizabeth Garrett Anderson, London: Methuen \& Co.

Morantz-Sanchez, R., 1999, Conduct Unbecoming a Woman: Medicine on Trial in Turn-ofthe-Century Brooklyn, New York: Oxford University Press.

Moscucci, O., 1990, The science of woman: Gynaecology and gender in England, 1800-1929, Cambridge: Cambridge University Press.

Playne's Lives of the Fellows Online, Royal College of Surgeons:

[http://livesonline.rcseng.ac.uk/biogs/E000206b.htm; accessed 5 March 2010].

Power, D’A. 2004 'Erichsen, Sir John Eric, baronet (1818-1896)', rev. B. A. Bryan, Oxford Dictionary of National Biography, Oxford University Press

[http://www.oxforddnb.com/view/article/8835, accessed 5 March 2010].

Reinarz J. 2009, Health Care in Birmingham: The Birmingham Teaching Hospitals, 17791939, Woodbridge: The Boydell Press.

Schlich, T., 2006, 'Risk and medical innovation: A historical perspective', in Schlich, T. and Tröhler, U., (eds) The Risks of Medical Innovation: Risk perception and assessment in historical context, Abingdon and New York: Routledge, pp.1-19.

Stanley, P., 2003, For Fear of Pain: British Surgery, 1790-1850, Amsterdam: Rodopi.

Thomas, O., 1971, Frances Elizabeth Hoggan, 1843-1927, Newport: n.p.

Wilde, S., 2009, 'Truth, Trust, and Confidence in Surgery, 1890-1910: Patient Autonomy, Communication, and Consent', Bulletin of the History of Medicine, 83.2, pp. 302-30.

Wilde, S., and Hirst, G., 2009, 'Learning from Mistakes: Early Twentieth-Century Surgical Practice', Journal of the History of Medicine and Allied Sciences, 64.1, pp. 38-77.

Worboys, M., 2000, Spreading Germs: Disease Theories and Medical Practice in Britain, 1865-1900, Cambridge: Cambridge University Press. 